\title{
Concept Construction on the Area of Oblique Triangles: A Lesson Study
}

\author{
Steve B. Anapi ${ }^{a *}$, Dave Carlos A. Calixtob, Romadel R. Peralta ${ }^{\mathrm{c}}$, Quezco F. Velasquez ${ }^{\mathrm{d}}$, Angelica Marie \\ Zamora $^{\mathrm{e}}$, Victorina D. Palanas ${ }^{\mathrm{f}}$, Levi E. Elipane ${ }^{\mathrm{g}}$ \\ a, b, c, d, e, f, g Philippine Normal University-Manila, Philippines \\ a*anapi.sb@pnu.edu.ph
}

Article History: Received: 10 November 2020; Revised 12 January 2021 Accepted: 27 January 2021; Published online: 5 April 2021

\begin{abstract}
This paper aimed to explain how students construct the concept of the area of oblique triangles. Through Lesson Study using the Theory of Didactical Situations, the researchers designed a research lesson with the raison d'être of improving the teaching of trigonometry. The research lesson was implemented to junior high school student-participants in a national high school in the Philippines, and was attended by a pool of observers. A priori and a posteriori analyses were conducted to validate the teaching and learning situations. Observations, notes, students' outputs, and post-lesson discussions and reflections were used in the analysis of didactical situations. After the conduct of the Lesson Study, the following themes emerged: (1) explicit mathematics didactical intentions are essential in analyzing students' constructed mathematical knowledge and learning, and (2) balancing adidactical situation and teacher facilitation allows independent learning for students.
\end{abstract}

Keywords: Concept construction; Didactical intentions; Theory of didactical situations; Adidactical situations; A priori analysis

\section{Introduction}

In terms of mathematics literacy, 2018 Philippine participation in PISA ranked the country second last among 79 participating countries. Also, the PISA 2018 National Report of the Philippines reported that the country achieved a significantly lower average score than the overall average score while $19.7 \%$ of Filipino students reached at least the minimum proficiency level [1]. This is expected since Filipino students' mathematics literacy historically performed lower in the National Achievement Test [1] and Trends in International Mathematics and Science Study (TIMSS) [2]. The quality of learning outcomes of students is the biggest challenge of Philippine basic education [1] since the implementation of the country's major curriculum reform - the Enhanced Basic Education Curriculum (K to 12 BEC)in 2013.

Guided by mathematics literacy problems, this study focused on how students construct mathematical concepts using didactical situations as a theoretical lens. By engaging in a Lesson Study, the researchers chose the area of oblique triangles as the mathematical organization for the research lesson. Several studies reported that students have difficulties in and fragmental understanding of trigonometry concepts [3, 4]. To further discuss this fragmental understanding of trigonometry concepts, the findings of Cetin [4] on mathematics education students' perceptions on conceptual understandings of trigonometric functions and their content development revealed that there is a high level of perception on trigonometric functions (i.e. angle and arc); but students do not understand their conceptual development. Likewise, students have visual imagery of the concept, but are not sufficient to grasp the concept and to understand its content development. This is also confirmed in the study of Fernandez, Hidalgo, and Rico [5] using the semantic triad: conceptual structure, representation, and sense to investigate students' understanding of trigonometry concepts. High school students do not possess an accepted meaning of the studied trigonometry concepts. The fragmental understanding of trigonometry can be explained by learning obstacles. In the qualitative study [6] regarding the ability of high school students to represent trigonometry concepts, three learning obstacles were found out. Ontogenic psychological obstacles pertain to the interests and motivations of students to learn trigonometry concepts, while conceptual ontogenic obstacles are difficulties of the students to comprehend the concept, and didactical obstacles are instructional designs that hinder the interconnectedness of concepts and do not provide alignment on students' previous experiences and knowledge.

Anchored on TDS, we aimed to design or engineer a mathematics instruction or didactical situations that could provide rich mathematical learning experiences for the students in building their understanding, deepen their ability to reason, and communicate mathematically. Eliminating didactical obstacles [6] and understanding students' mental constructions, our rationale for improving the teaching of triangle trigonometry specifically the 
process of students' concept construction on the area of oblique triangles gave directions to the Lesson Study we opted with analysis from the theoretical perspectives of TDS.

\section{Literature Review}

We emphasized the teaching and learning of the triangle because we believe that the study of triangles is one of the most important concepts in the understanding and learning of geometry and trigonometry. From an epistemological perspective, the area of oblique triangles connects different mathematical concepts in the fields of geometry and trigonometry. The area of the triangle is known to students since it is given in elementary mathematics and reinforced in high school mathematics while right triangle trigonometry and trigonometric functions are introduced in high school mathematics. The abstraction of the area of oblique triangles relates these mathematical contents and in this study is emphasized as didactical variables.

\section{Theory of Didactical Situations (TDS)}

TDS explains the inherently complex situation involving interactions among teacher-student-content in a given milieu [7, 8]. Generally speaking, the theory is concerned with comprehensively explaining the interaction between the learner and the milieu. Explained briefly, "[ $\mathrm{t}]$ he milieu typically includes other learners, the concepts learned by students as well as prior conceptual machinery present in the student's repertoire and available for use" [8]. Learning, in the TDS perspective, is making sense of situations in a milieu and coping with this milieu in developmental ways, therefore, taken in the context of a theory of situations, "knowledge is the outcome of the interactions between the student and a specific milieu organized by the teacher in the framework of a didactic situation" [9].

In the context of mathematics teaching practice, the understanding of the theory can help teachers engineer mathematical situations to facilitate students' understanding. Furthermore, in the context of mathematics education research, the theory focuses on developing conceptual tools for studying and modeling learning situations to understand how learning happens [10]. There are different phases of didactic situations based on the role that the teacher plays with the student-milieu scheme (i.e. situation of action, formulation, validation, and institutionalization). Descriptions and explanations of the situations ofaction, formulation, validation, and institutionalization are based on the concept of feedback [11] and dialectic [11].

In brief, according to Brousseau [12] "the modern conception of teaching, therefore, requires the teacher to provoke the expected adaptation in her students by a judicious choice of problems (emphasis from the author) that she puts before them" and that problem-situation is the milieu". The teacher then organizes the problemsituation for students to engage and interact with the milieu. In this situation, the student is now in adidactical situation (learning situation) - a learning situation where the teacher does not interfere with the students' interaction with the milieu [12]. Being left in the learning situation, the student will either motivate to solve or create the solution to the problem-situation. In here, feedback is taken as communication of information while dialectic is the method that turns the information communicated into knowledge in the student-milieu system (including the management of contradictions and obstacles). Further, “...the construction of meaning, as we understand it, implies a constant interaction between the student and problem-situations, a dialectical interaction (because the subject anticipates and directs her actions) in which she engages her previous knowing, submits them to revision, modifies them, completes them or rejects them to form new conceptions" [11].

Adidactical situation has three phases, i.e. action, formulation, and validation. According to [11, 13] in action phase, the teacher is an organizer. S/he chooses and organizes a problem-situation or milieu. The teacher's intention in giving the milieu is that the students engage and adopt the milieu and after which s/he devolves from the situation, while in formulation phase, after the situation of action, the teacher re-enters in the didactical situation. This time, the teacher serves as chair in the exchanges of communication amongst students and making sure that all formulations made by individual students are "visible", and in validation phase, the role of the teacher is much visible. S/he acts as a chair in a scientific debate amongst students. Also, s/he intervenes in the debate to organize the debate, make students' aware of the possible inconsistency, and to make students use precise mathematical concepts and language. In summary, when the teacher and students interact in the learning situation, i.e. the teacher organizes the problem-situation/milieu and the students inquire if they understand well the problem-situation, then they are in a didactical situation.

Note however that, a milieu devoid of didactical intentions is inadequate to provoke in the student the knowledge that the teacher wishes her to learn [11]. The method of didactic engineering (conception, design, and implementation of the didactical situations including the predictions of properties of knowledge and the realization — checking if the predictions were correct) considered these didactical intentions. Further, Artigue [14] defines didactic engineering as a methodology that is based on a controlled design of teaching sessions of which the design is subjected to experimentation and the evaluation of the a priori and a posteriori analyses were its 
internal mode of validation. Moreover, a priori analysisdetermines these didactical intentions in the process of didactical engineering. In the context of TDS, a priori analysis is a teachers' tool when planning their lessons [12]. Theoretically, a good a priori analysis is a prerequisite if one wants a successful didactical situation.

Now, taken in the context of mathematics education, as Bosch and Chevallard [15] posited that mathematical knowledge could only be constructed and/or acquired through a structured activity where students are put in a situation where they interacted in a milieu. Thus, TDS is a holistic theory that explains how mathematics teachers can design and redesign teaching situations for optimal mathematics learning.

This paper aims to explain students' construction of mathematical concept as captured by the interactions among student, teacher, and mathematical knowledge with TDS as a guiding framework in explaining the didactical phenomena happened in the mathematics-learning environment. Using Lesson Study as a form of classroom-based inquiry, the researchers planned and implemented the research lesson to look into how students were able to construct the concept of the area of oblique triangles.

\section{Methods}

We conducted a Lesson Study to improve the teaching and learning of the area of oblique triangles. Lesson Study is a collaborative teacher professional development model that allows teachers to closely examine the lessons and inquire about teacher's instructional practices [16, 17, 18]. Lesson Study is an effective teacher professional development approach because it incorporates the following aspects: "it is site-based, practiceoriented, focused on student learning, collaboration-based, and research-oriented" [16]. Although Lesson Study is a professional development approach for teachers, teacher behavior is less emphasized but rather, its entire process is focused on student learning and collecting substantial information from the live classroom interaction [19].

We opted to use the Lesson Study because this method enabled us to design/engineer a lesson to make students' learning visible and to explore and validate the didactical phenomena. The process of Lesson Study enables us to not only study the didactical phenomena but also as Murata [16] contends, to test our teaching approach in a live context and be able to investigate how students learn, specifically how students mentally constructed the meaning of area of oblique triangles based from the didactical situation of the designed lesson. Also, the approach helped us to determine the key aspects of our lesson (i.e. previous learning experiences relative to the students' concept of the triangle and right triangle trigonometry). From this point, we were able to anticipate how students will respond to different learning activities of our lesson and this enabled us to focus on student's different thinking processes and the didactic process at hand.

Lesson Study is an appropriate method with TDS as the theoretical lens to investigate the mental constructions of students as influenced by the didactical situation. Research lesson (planned and implemented lesson) was emphasized in the conduct of the Lesson Study as this is central to the process [16] and is designed to improve student achievement [19]. This part of the Lesson Study is the core element of the process as this phase helped us to investigate how students construct the concept of the area of the oblique triangle. The Lesson Study process lasted for three weeks. The research lesson was implemented on March 9, 2020, and took one hour to finish.

\section{Participants}

This study involved 35 Grade 9 junior high school student-participants from an urban school in a city in Laguna, Philippines, the researchers, four Mathematics teachers of the said school, School Head/ Principal, and four Ph.D. in Mathematics Education students. Implementation of the research lesson was well coordinated with the participating school and considered the student-participants regular schedule.

\section{Methodology}

\section{Procedure}

This study carefully followed the following phases in the conduct of the Lesson Study: planning, implementation, and post-lesson discussion.

\section{Planning}

We collaborated in setting the goal and planning of the research lesson by doing several meetings, brainstorming activities, designing the lesson, and writing the lesson plan as designed. The research lesson centered on finding the area of oblique triangles. With TDS in mind, the planning of the research lesson was anchored on didactic engineering. Hence, a priori analysis is a precondition in designing the research lesson. Our use of Lesson Study coupled with the theoretical lens of TDS is on the belief of the principle in lesson study as posited by Murata [16] who stated, "As they [teachers] plan, they anticipate students' possible responses and craft the details of the lesson. Teachers come to know the key aspects of the lesson, to anticipate how students may 
respond to these aspects, and to explore different thinking and reasoning that may lie behind the possible responses".

We designed a series of tasks (three integrated collaborative student activities): (1) area of an equilateral triangle; (2) area of a scalene-acute triangle; and (3) area of a scalene-obtuse triangle (see Figure 1). In the planning of the research lesson, we carefully thought of ways of not intervening with the student interactions with the milieu during the adidactical situations. Thus, we believed that the main task of finding the area of oblique triangles with the aid of triangle cutouts as the major component of the designed milieu would put students in adidactical situation.



(a)

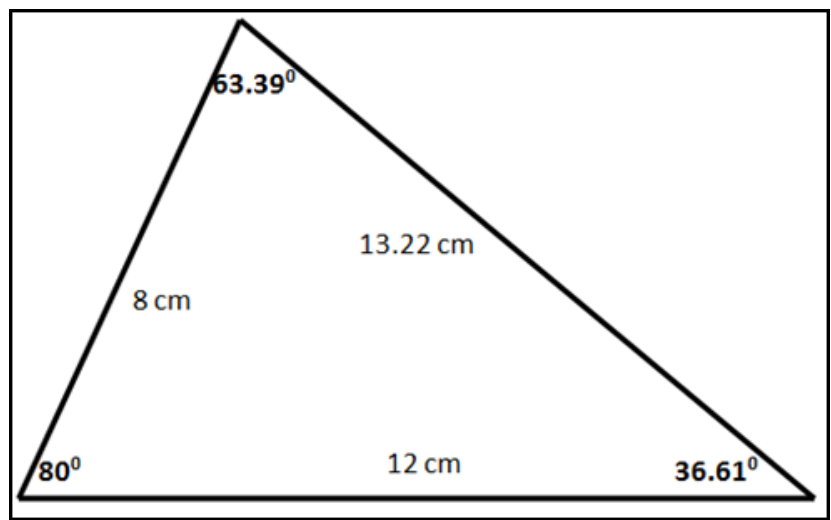

(b)

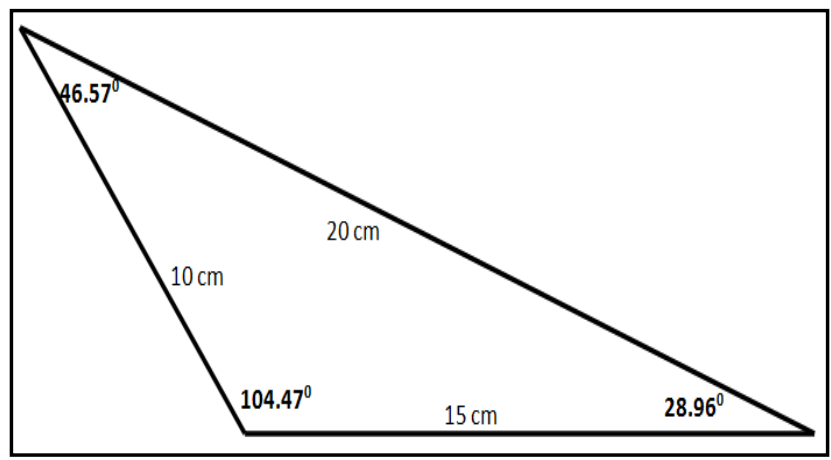

(c)

Figure 1. Obtuse triangle cutouts-(a) equilateral triangle, (b) scalene-acute triangle, and (c) scalene-obtuse triangle

Guided by TDS, these didactical intentions are our predictions on the didactical situations that would take place during the research lesson. We hoped to observe the following from the design of the research lesson:

a. Given the main task, the students will first activate their knowledge on the area of the triangle (identifying height and base, recalling the formula of area of the triangle, i.e, $A_{\Delta}=1 / 2[\mathrm{bh}]$ computing for the area). 
b. Height of the oblique triangle (height problem) surfaces as problem-situation/milieu. Since no available formula for the area of the oblique triangle and any side chosen will be the base, using the cutouts, students will geometrically identify the height of the triangle.

c. With the geometrical identification of height (either they crease the cutout or draw the height using straightedge), students will be left with right triangles. The height problem still surfaces as a problem-situation (this time as procedural). Students will use another knowledge, i.e. finding the lengths of parts of the right triangle using a trigonometric function. Students will use the sine function as the only viable trigonometric function at hand to determine the height.

In the case of the equilateral triangle (first task), the students are also predicted to use their knowledge on solving the right triangle using the Pythagorean theorem or to use their knowledge on the special right triangle $\left(30^{0}-60^{0}-90^{0}\right)$.

d. Use the computed height and preferred base of the triangle to compute the area of the oblique triangle.

\section{Implementation}

A semi-detailed lesson plan was prepared for the research lesson. Oblique triangle/ Non-right triangle cutouts were used as the main material and central for the analysis of students' concept construction of the area of the oblique triangles.

During the actual implementation, most of the planned and designed activities of the research lesson were executed. Some of the challenges faced during the actual implementation were the duration of mathematics class, the teacher's pacing, and the number of students' tasks. One hour was not enough to execute the research lesson. Also, there were many students' tasks and after each task, there was immediate feedback from the teacher, and students were encouraged to communicate and reason mathematically in a whole class setup. In the review activity, there was a big amount of time consumed and the teacher's pacing becomes slower since the teacher emphasized the knowledge that would be activated during the problem-situation.

In the problem-situation or main task, the students were able to find the area of the equilateral triangle and scalene acute triangle (including also the interchange of heights and bases). Students were able to derive the formula of the area of the oblique triangle using the two triangle cutouts. Since time was limited and we designed the lesson for students to publish their thinking and communicate and reason mathematically, the teacher was not able to give the task on the area of the scalene-obtuse triangle and proceeded with the abstraction of students' learning using the two finished tasks.

Researchers and invited observers collected data on students' learning via observation and note-taking. The observers were able to move around and observed each student and their groups while doing the tasks. Some of the data collected are from the observers' short interviews with individual students while they are engaged in the problem-situation.

\section{Post-Lesson Discussion}

Soon after the research lesson ended, debriefing and post-conference were held through the facilitation by a university professor. Members of the research group, other Ph.D. students, and invited observers attended the post-conference. Data collected from the different observations were examined and reflected upon during this stage. This was done to examine what transpired in the entirety of the research lesson and to critically reflect on the teaching-learning experience. We collected all observations, comments, suggestions, and field notes from the different viewers of the lesson study. In this stage, observers were able to communicate what they have observed. We took all comments and suggestions constructively with a collaborative and shared effort atmosphere.

\section{Data collection tools}

Data collected in this study includes students' outputs, observers' notes, and post-lesson discussions and reflections. Short interviews of observers while students are engaged in the task were reflected in post-lesson reflections. No follow-up interviews on selected students were conducted.

\section{Data Analysis}

In analyzing the data collected, we used a priori analysisand a posteriori analysis. A priori analysis in the planning stage of the Lesson Study was a necessary condition because this would allow us to explain the "...differences in complexity between the situations, between the procedures or between the cognitive models which characterize them" [11]. The use of a priori analysis to understand how high school students construct the concept of the area of oblique triangles when put in a didactical situation draws from the reason that it takes into account the mathematical epistemology [20] i.e. the mathematical contents or concepts inherent in the 
construction of the concept of the area of oblique triangles. TDS was a suitable theoretical lens in this study because the theory gives importance to this epistemological perspective. The a priori analysis for the research lesson served two purposes, predicting outcomes and assessing the efficiency of the designed learning tasks with respect to the intended learning objectives.

A posteriori analysis was used to validate [7] the didactical situations that happened in the research lesson based on the data collected from observations, notes, student outputs, and post-lesson reflections. As Artigue [21] stated, the connection between a priori and aposteriori analyses puts the designed lesson to the test. The comparison and connection between the two analyses would provide insights and reflections on the complexity of mathematics teaching and learning.

\section{Results and Discussions}

The following emergent themes were extracted from the Lesson Study: (1) explicit mathematics didactical intentions are essential in analyzing students' constructed mathematical knowledge and learning, and (2) minimum teacher supervision and intervention in the didactical situations aid students in attaining deeper mathematical understanding.

\section{Explicit mathematics didactical intentions are essential in analyzing students' constructed mathematical knowledge and learning}

Note that according to TDS, a priori analysis is a function of mathematical content. We considered the students' knowledge of the concepts of triangle trigonometry specifically on the concept of the sine function in right triangles.

From a priori analysis, we planned and designed the research lesson such that the didactic intentions were made as explicit as possible. Based on our collective reflections on the students' outputs, notes of observers, comments, and suggestions of observers during the post-conference, the following cognitive model that characterized the didactical situations $(D S)$ on Lesson Study emerged as predicted with respect from the $a$ priori analysis.

The didactical variables considered in the a priori analysis validated and reflected upon in the $a$ posteriori analysis were (a) knowledge on the area of triangle, (b) height problem, (c) knowledge on right triangle trigonometry. As we predicted, students were able to construct the concept of the area of the oblique triangle (see Figure 2).

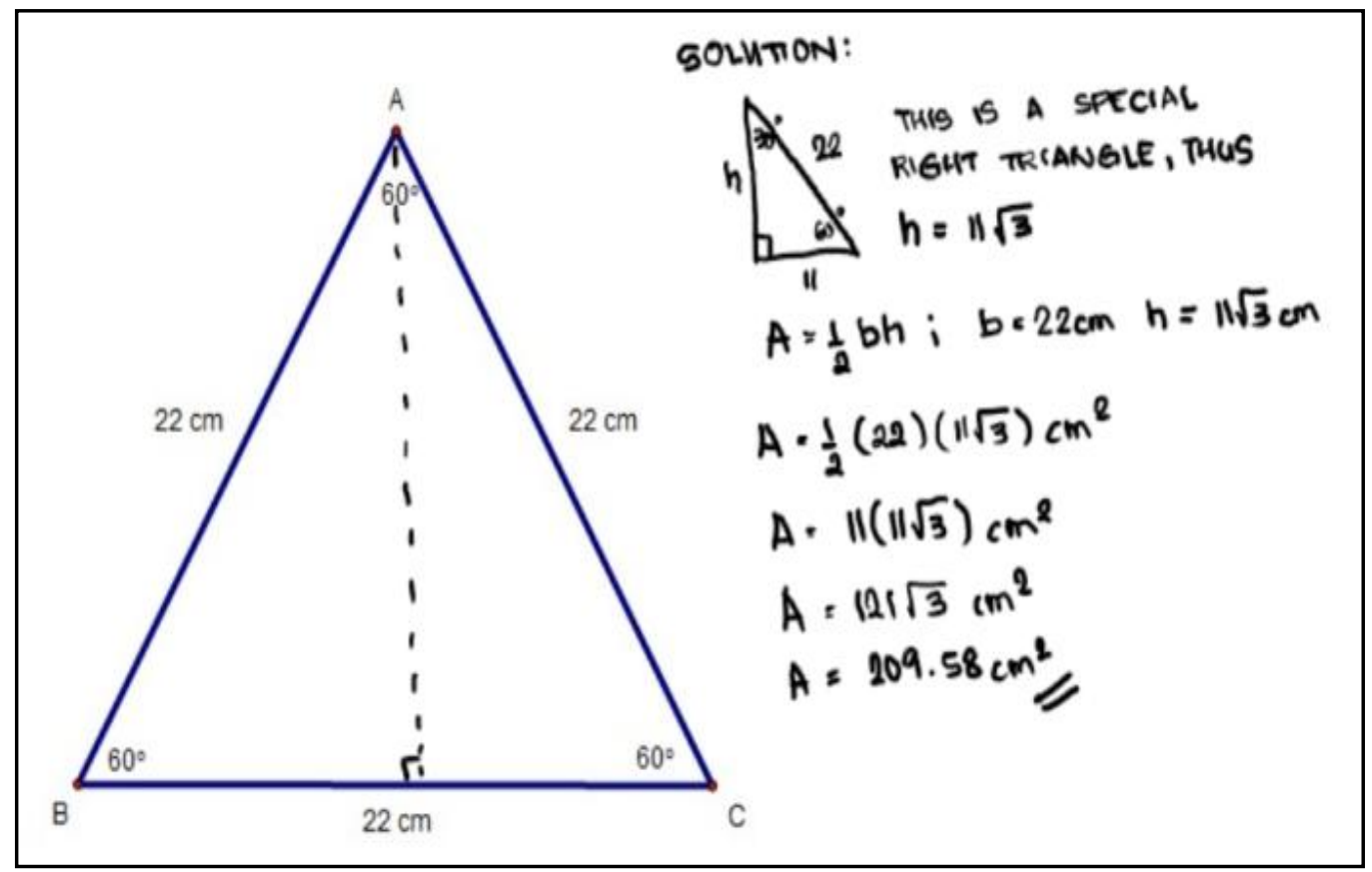

(a) 


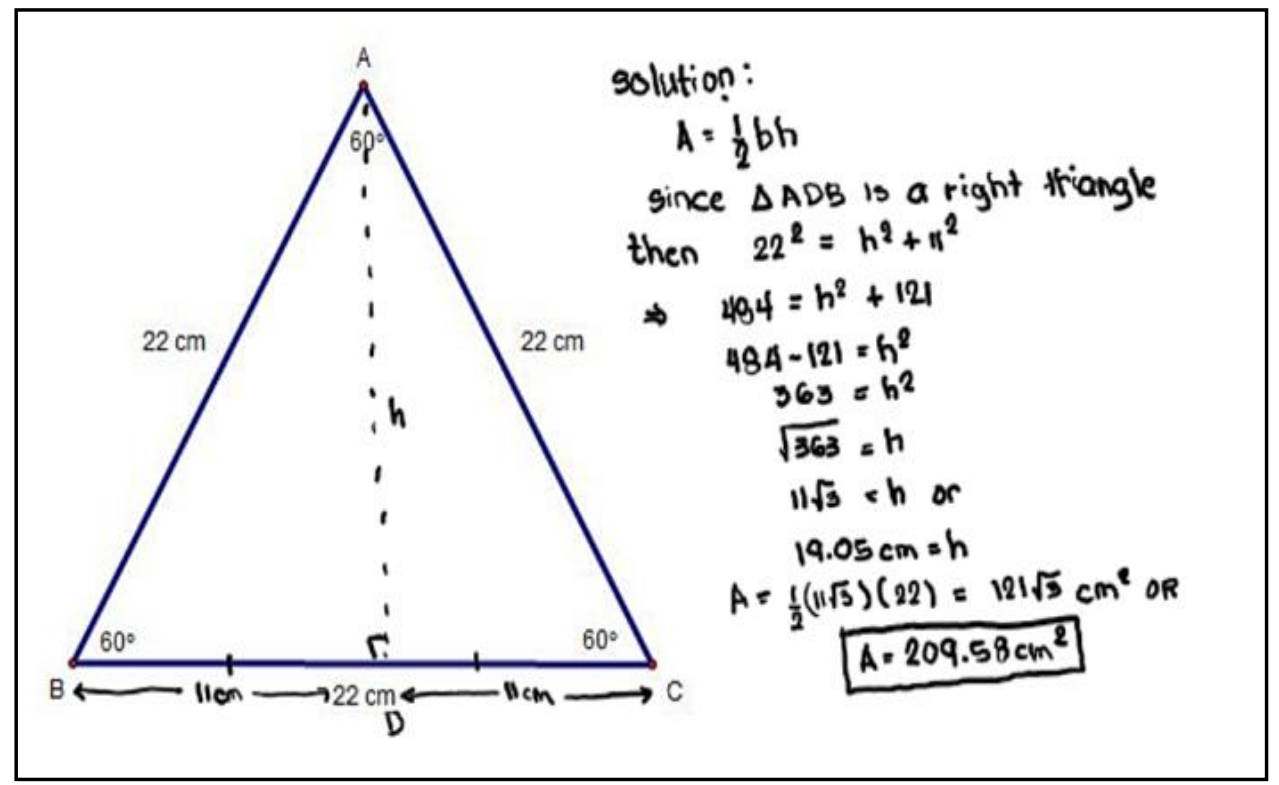

(b)

Figure 2.Students' outputs—-solution strategies during the tasks

From the explicit didactical intentions as designed by researchers on the research lesson, students were able to construct and acquire the concept of the area of oblique triangles. How students constructed and acquired the mathematical knowledge in a didactical situation is attributed to the $a$ priori as "...to be only a necessary prologue to learning" [11]. The process of construction or management of meaning is the object of the theory of situations.

The milieu or problem-situation (height problem with the aid of triangle cutouts, collaboration among group members, and the main task of obtaining an area of the oblique triangle) in the research lesson paved the way for students to work independently and collaboratively to construct the concept or meaning of area of oblique triangles. From the cognitive model presented, one can see that the milieu connected three didactical variables in the teaching situation.

The milieu made the dialectic interaction possible through feedback and student acting and adapting to it. This confirmed that people learn with interactions with objects [22]. As what observed, when the students were engaged in the height problem and are motivated to solve the problem through creasing the cutout or drawing a perpendicular line from one vertex to the opposite side, and the teacher not intervening in the process, the students were in the adidactical or learning situation where they used their previous knowledge, i.e. knowledge on right triangle trigonometry through sine function to solve the problem. In this situation, there was constant feedback and action as noted from the questions they raised among their group members, e.g. how to solve for the height?; what formula to use, sine? cosine?; this is a right triangle, right? This didactic phenomenon is seen as a dialectic interaction [11].

From the collective observations, we observed and reflected on the following model of situations (based on [11], see Figure 3). The cognitive model previously stated was incorporated in this model to explain the didactical phenomena that happened during the action stage of the research lesson. 


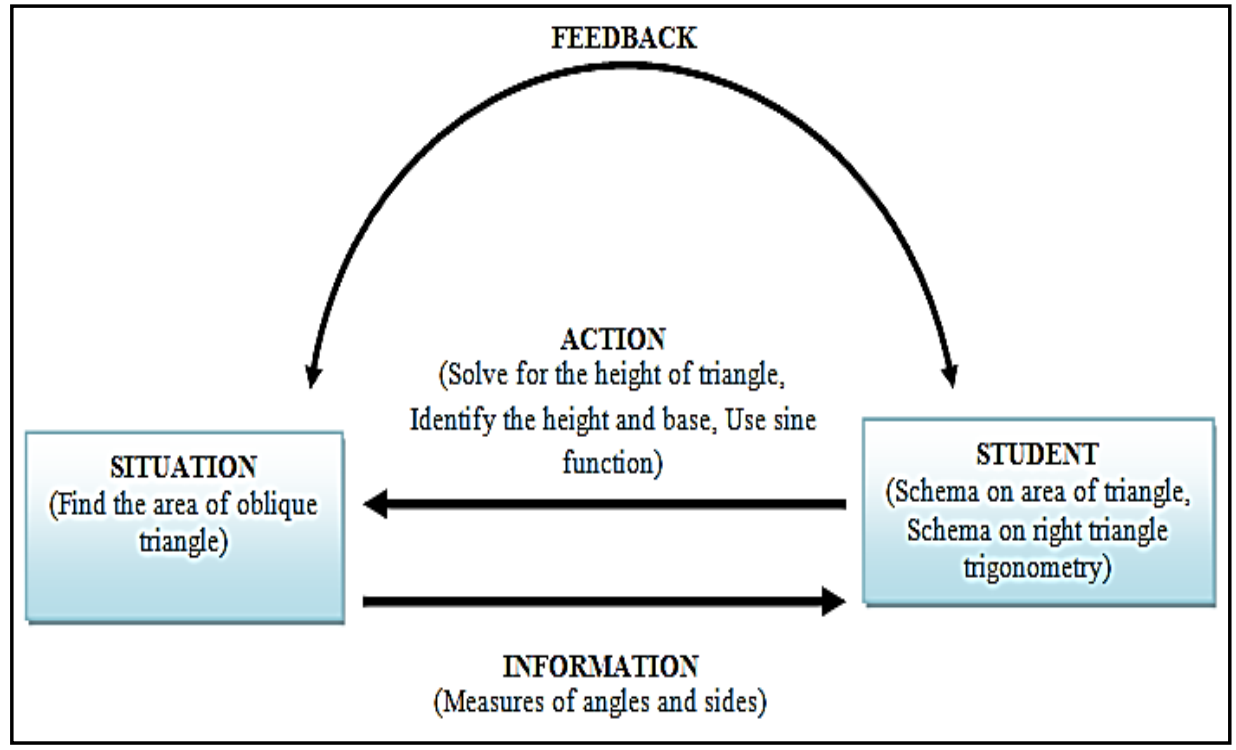

Figure 3. Model of situations during the action phase of the research lesson (individual process)

From the collective observations, we observed and reflected on the following model of situations (based on [11], see Figure 3). The cognitive model previously stated was incorporated in this model to explain the didactical phenomena that happened during the action stage of the research lesson.

The model explains the student's concept construction of the area of the oblique triangle. As designed by the researchers and reflected upon in the a posteriori analysis, students were able to integrate through the help of the milieu the conceptual and procedural knowledge on the area of the triangle, height, base, right triangle, and the sine function.

Our finding of the explicitness of didactical intentions is in support of the field of didactics of mathematics. The focus of mathematics teaching and learning should be on the study of the transposition of intended mathematical knowledge through didactical systems and the interactions connected with the teaching-learning processes.

\section{Balancing adidactical situation and teacher facilitation allows independent learning for students}

As part also of a priori analysis of the research lesson, we designed the series of tasks where the finding of the area of the equilateral triangle is the first of the student activities because they posited that students could easily be solved for the measure of the height of the said triangle (see Figure 4).

We intentionally designed the research lesson such that the first of the tasks is to find the area of the equilateral triangle (see Figure 2). We believe that students without a teacher's intervention could interact easily with the cutout of the equilateral triangle by simply folding/ creasing the cutout and other parts of the triangle can be determined geometrically (e.g. $11 \mathrm{~cm}$ length, $30^{\circ}$, and $90^{\circ}$ angle measures).

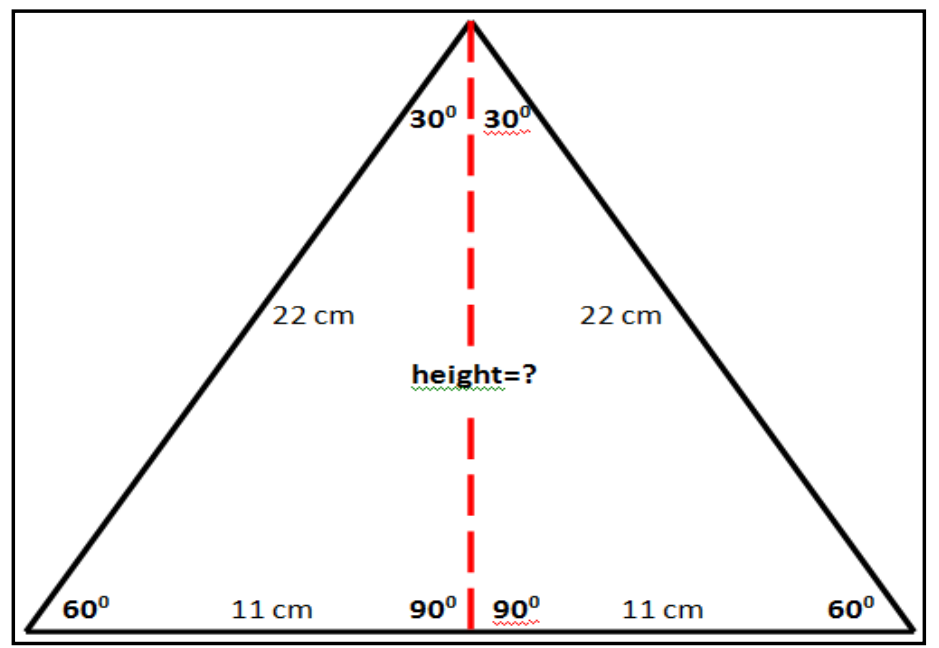


Figure 4. Solution strategy for determining the area of the equilateral triangle

We also believe that the activity on finding the area of the equilateral triangle would become a scaffold for the next tasks. Also, we decided to add the task of changing the location of the height and the base of the two remaining triangle cutouts. We intentionally planned this design, with the a priori analysis that students would acknowledge conceptually and strategically that the area of the two remaining triangle cutouts remains the same even when heights and bases of the triangles are interchanged.

Inherent in the design of the research lesson is a priori analysis of the collaboration of students. We believed that students would be able to construct mathematical knowledge both individually and collectively. Collaboration among students was included in the design because we wanted students to communicate and reason mathematically. We designed the class groupings such that each grouping is composed of 3-4 students. To internally validate these didactical intentions, a posteriori analysis is needed. The following validation from the $a$ posteriori analysis were reflected.

From the data collected, we observed the different stages of adidactical situations:

Action phase. In the first task of finding the area of the equilateral triangle, students interacted with the milieu. Without teacher intervention, they were in adidactical situation $[11,13]$. The student acted upon the cutout by creasing or drawing the height without being told to find the height. We infer that the cutout as an artifact from a design perspective was able to mediate the intended mathematical knowledge as it serves its purpose to support the unfolding of the specific mathematical feature of oblique triangles.

In the TDS point of view, the height problem was internalized and acted upon. Students used the previous knowledge on the area of the triangle, geometrical understanding of height, and knowledge on the right triangle trigonometry to act upon the problem. The milieu integrates these didactical variables. This didactic phenomenon is the didactical situation of action [11].

Formulation phase. From the students' output, the second task (finding the area of a scalene-acute triangle) enabled to situate the students to formulate a viable solution strategy to solve the problem situation. The small group collaboration and discussion enabled students to communicate and reason mathematically (see Figure 5).

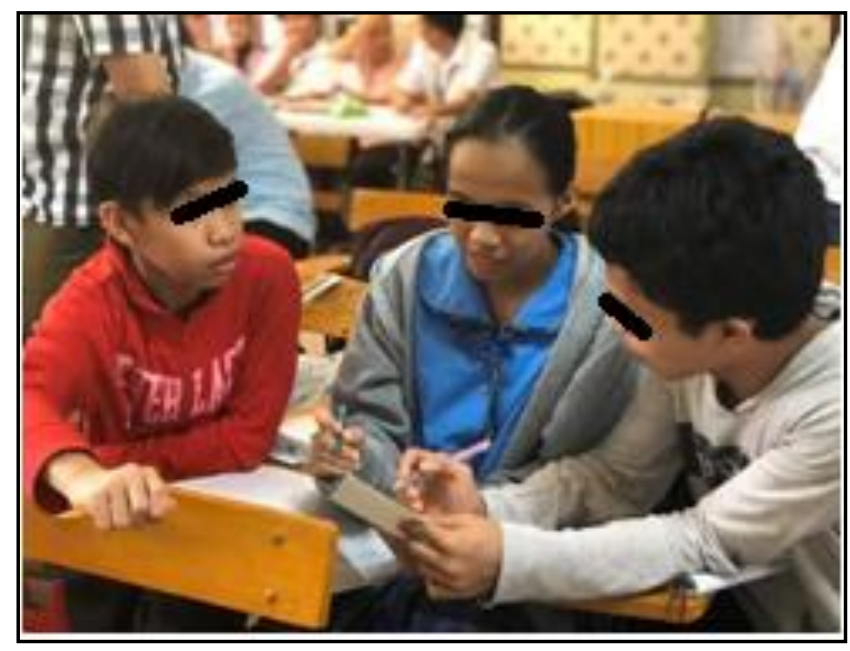

Figure 5. Small group collaboration and discussion

In this stage, the researchers have observed that students were puzzled about how to get the area of the given triangle. Students used the same solution strategy of geometrically identifying the height (creasing or drawing), but confronted again with the height problem. At this stage, the knowledge on right triangle trigonometry, i.e. the use of sine function became the viable solution strategy to the problem-situation. Again, students acted upon the milieu. The formulation of a viable solution strategy coupled with small group discussion confirms what Brousseau [11] called the didactical situation of formulation.

Validation phase. The task given to the students was to change the location of the height and base of the given scalene-acute triangle. From the data collected, students were able to present and explain to the whole class their solution strategies (see Figure 6). Looking at students' outputs and presentations, there was a convergence of solution strategies (all of them used sine function as viable solution strategy for the height problem) and answers on the area of the given triangle are approximately the same. Affirmation of solution strategy was confirmed when students did not question their classmates' answers. The solution strategy became proof of the problem-situation. 
As Brousseau [11, p. 15] stated, "The consideration of a proof is a reflexive attitude. The proof must be formulated and present while being considered, and therefore most often written, and must be able to be compared with other written proofs also dealing with the same situation. In general, proof will be formulable only after having been used and tested as an implicit rule either in action or in discussion".

Hence, in TDSs' view, this is a didactical situation of validation.

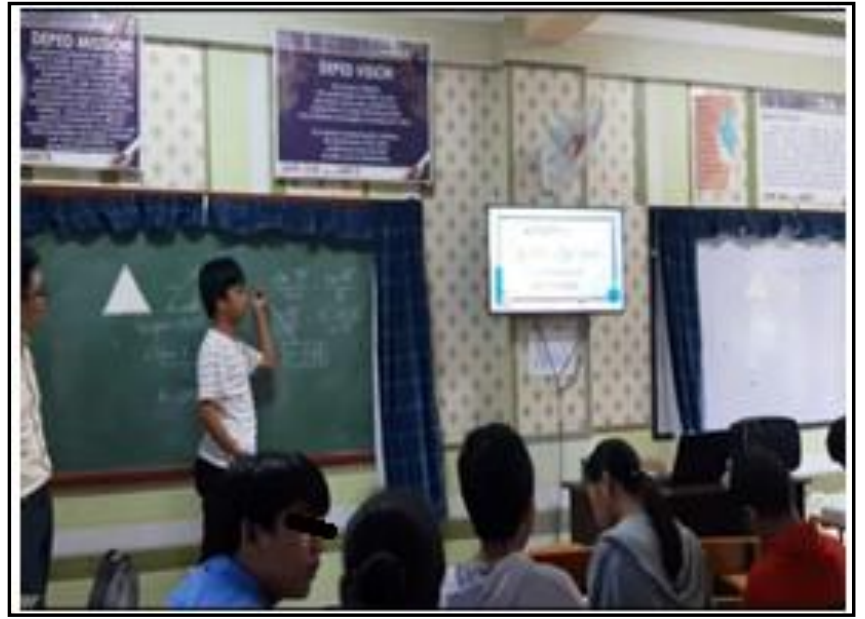

Figure 6. A student presenting their solution strategy

In all of the stages mentioned, the teacher maintained the role of facilitator of learning, students were able to interact with the milieu and were able to communicate and reason mathematically with their peers, therefore, balancing adidactical situation and teacher facilitation while the student is interacting with the milieu aid in meaning-making and understanding of the intended mathematical knowledge, moreover, it allows independent learning for students.

\section{Conclusion}

Based on the findings of this study, using TDS as our theoretical lens, we highlight that in the didactics of mathematics, explicit mathematics didactical intentions are essential in analyzing students' constructed mathematical knowledge and learning, and balancing adidactical situation and teacher facilitation allows independent learning for students. The findings of this study contribute in developing mathematical theory and practice. On the other hand, minimum modification of the tasks designed using a priori and a posteriori analyses are considered to improve the engineered lesson. Guided by TDS as a theoretical lens, the success of the conduct of the lesson study was attained. The collaborative nature of Lesson Study led us to realizing better plans for the next cycle of this study. Further research that uses didactic engineering or design research methods is encouraged to validate the findings of this study.

\section{Limitations and Future Studies}

The Theory of Didactical Situations is used to explore how students construct the mathematical concept through the student-milieu system. For future directions, cycle of concept construction through the SOLO (Structure of Observed Learning Outcomes) Model may be used as a theoretical lens. On a similar note, follow-up interviews with students will add substantial analyses on the concept construction. Also, a second cycle of Lesson Study is desired to improve the designed lesson on the area of oblique triangles

\section{References}

Department of Education. (2019). PISA 2018 national report of the Philippines. Pasig City, Philippines.

Bernardo, J. (2020, December). PH ranks last among 58 countries in grade 4 math, science: study. ABS-CBN News.

Weber, K. (2005). Students' understanding of trigonometric functions. Math. Educ. Res. J, 17(3), 91-112.

Cetin, O. F. (2015). Students' perceptions and development of conceptual understanding regarding trigonometry and trigonometric function. Educational Research and Reviews, 10(3), 338-350. https://doi.org/10.5897/ERR2014.2017

Fernandez, E. M., Hidalgo, J. F., \& Rico, A. L. (2019). Meaning and understanding of school mathematical concepts of secondary students: The study of sine and cosine," EURASIA Journal of Mathematics, Science and Technology Education.,15(2). 
Komala, E., Suryadi, D., \& Dasari, D. (2020). Learning obstacle related to the ability of high school student representation to the trigonometry concept. The 2nd International Conference and Innovation Exhibition Global Education (ICEGE), 43-49. https://doi.org/10.22236/ie.v1i1.107

Artigue, M. (1994). Didactical engineering as a framework for the conception of teaching products. In R. Biehler, R. W. Scholz, R. Sträßer, B. Winkelmann (Eds.). Didactics of Mathematics as a Scientific Discipline, Kluwer Academic Publishers, 27-39.

Sriraman, B., \& English, L. (2010). Surveying theories and philosophies of mathematics education. In B. Sriraman \& L. English (Eds.). Theories of Mathematics Education: Seeking New Frontiers, Springer, 22. http:/doi.org./10.1007/978-3-642-00742-2

Balacheff, N. (1993). Artificial intelligence and real teaching. In C. Keitel, \& K. Ruthven (Eds.), Learning from Computers: Mathematics Education and Technology, Berlin: Springer-Verlag, 131-158.

Miyakawa, T., \& Winslow, C. (2009). Didactical designs for students' proportional reasoning: An open approach and a fundamental situation. Educational Studies in Mathematics, 72(2), 199-218. http://doi.org/10.1007/s10649-009-9188-y

Brousseau, G. (2002). Theory of didactical situations in mathematics: Didactique des mathématiques, 19701990. N. Balacheff, M. Cooper, R. Sutherland, \& V. Warfield (Eds.), Kluwer Academic Publishers, 33, 8283, 172.

Brousseau, G. (1998). Théorie des situations didactiques. In N. Balacheff, M. Cooper, R. Sutherland, \& V. Warfield (Eds.), Grenoble: La Pensée sauvage, 30.

Måsøval, H. (2011). Factors constraining students'establishment of algebraic generality in shape patterns. PhD Thesis, University of Agder, excerpt: Chap. 2, 32-66.

Artigue, M. (2014). Didactic engineering in mathematics education. In L. Sriraman (eds.) Encyclopedia of Mathematics Education. Springer, Dordrecht. https://doi.org/10.1007/978-94-007-4978-8_44

Bosch, M., \& Chevallard, Y. (1999). La sensibilité de l'activité mathématique aux ostensifs. Objet d'étude et problématique. Recherches en Didactique des Mathématiques, 19(1), 77-123.

Murata, A. (2011). Introduction: Conceptual overview of lesson study. In L. C. Hart, A. S. Alston, \& A. Murata (Eds.). Lesson Study Research and Practice in Mathematics Education: Learning Together. Springer Science+Business Media B.V., 1-12. http://doi.org./10.1007/978-90-481-9941-9

Saito, E. , \& Atencio, M. (2013). A conceptual discussion of lesson study from a micropolitical perspective: Implications for teacher development and pupil learning. Teaching and Teacher Education, 3(1), 87-95. http://dx.doi.org/10.1016/j.tate.2013.01.001

Elipane, L. (2017). Introducing Lesson Study as a Professional Development Model in the Islands of the Philippines. Advanced Science Letters, 23(2), 1126-1129.

Puchner, L. D. \& Taylor, A. R. (2006). Lesson study, collaboration, and teacher efficacy: Stories from two school-based math lesson study groups. Teaching and Teacher Education, 22(7), 922-934. http://dx.doi.org/10.1016/j.tate.2006.04.011

Kidron, I. (2019). Comparing a priori analyses. Eleventh Congress of the European Society for Research in Mathematics Education, Utrecht University, Utrecht, Netherlands.

Artigue, M. (2014). Perspectives on design research: the case of didactical engineering. A. Bikner-Ahsbahs, C. Knipping \& N. Presmeg (Eds.). Approaches to qualitative research in mathematics education, Springer, 467496. https.//doi.org./10.1007/978-94-017-9181-6_17

Chevallard, Y., Bosch, M., \& Gascón, J. (1998). Estudiar matemáticas: el eslabón perdido entre enseñanza y aprendizaje. SEP/ICE Universitat de Barcelona. 